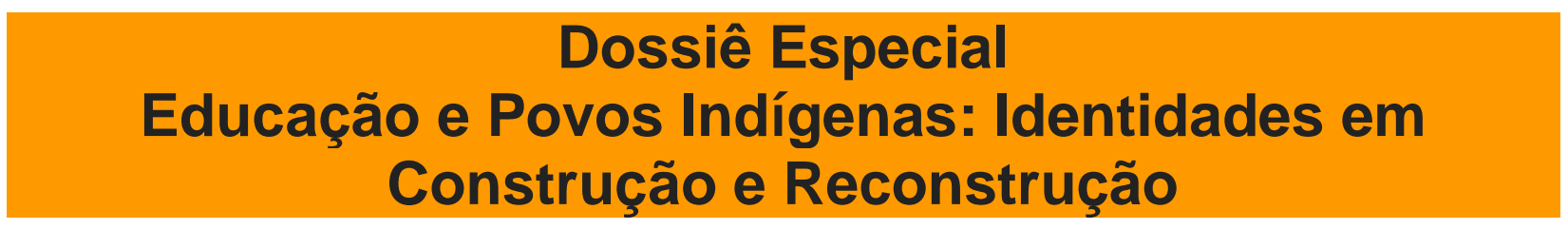
arquivos analíticos de políticas

\title{
educativas
}

Revista acadêmica, avaliada por pares, independente, de acesso aberto, e multilíngue

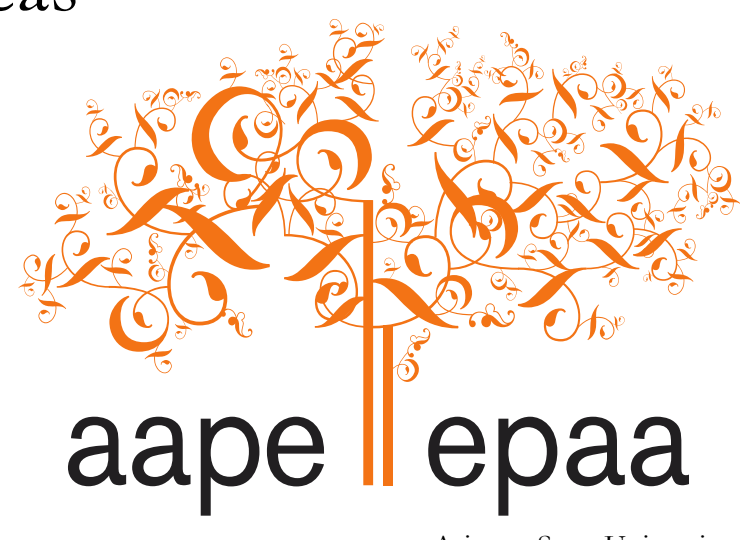

Arizona State University

Volume 28 Número $73 \quad 4$ de maio de $2020 \quad$ ISSN 1068-2341

\section{Trajetórias Indígenas na Universidade: O Direito ao Ensino Superior no Rio de Janeiro}

\author{
Kelly Russo \\ ¿。 \\ Edson Araújo Diniz. \\ Universidade do Estado do Rio de Janeiro \\ Brasil
}

Citação: Russo, K., \& Diniz, E. A. (2020). Trajetórias indígenas na universidade: O direito ao ensino superior no Rio de Janeiro. Arquivos Analíticos de Políticas Educativas, 28(72).

https://doi.org/10.14507/epaa.28.4708 Este artigo faz parte do dossiê especial, Educação e Povos

Indígenas - Identidades em Construção e Reconstrução, editado por Juliane Angnes e Kaizo Iwakami Beltrao.

Resumo: Este artigo tem por objetivo discutir o acesso e a permanência de estudantes indígenas no ensino superior, a partir de um trabalho de campo realizado com jovens de diferentes etnias, universitários de instituições públicas e privadas no estado do Rio de Janeiro. Através de um trabalho de revisão histórica sobre o direito à educação das populações indígenas no país, da análise de documentos e de entrevistas realizadas aos estudantes, constatamos a necessidade de se aprimorar o processo de ingresso e as condições de permanência desses estudantes, executando e viabilizando 
uma ampliação das políticas públicas de ação afirmativa voltada para a inclusão das populações indígenas no ensino superior no estado do Rio de Janeiro.

Palavras-chave: Universitários Indígenas; Ação Afirmativa; Ensino Superior

\section{Indigenous trajectories at the university: The right to higher education in Rio de Janeiro}

Abstract: This article aims to discuss the access and permanence of indigenous students in higher education, based on a field work conducted with young people of different ethnicities, university students from public and private institutions in the state of Rio de Janeiro. Through a work of historical revision on the right to education of the indigenous populations in the country, the analysis of documents and interviews conducted to students, we verified the need to improve the entry process and the conditions of permanence of these students, executing and making feasible an expansion of public affirmative action policies aimed at the inclusion of indigenous populations in higher education in the state of Rio de Janeiro.

Keywords: Indigenous students; Affirmative Action; Higher education

\section{Trayectorias indígenas en la universidad: El derecho a la educación superior en Río de Janeiro}

Resumen: Este artículo tiene como objetivo discutir el acceso y la permanencia de los estudiantes indígenas en la educación superior, en base al trabajo de campo realizado con jóvenes de diferentes etnias, estudiantes universitarios de instituciones públicas y privadas en el estado de Río de Janeiro. A través de un trabajo de revisión histórica sobre el derecho a la educación de las poblaciones indígenas en el país, a través del análisis de documentos y entrevistas realizadas con estudiantes, descubrimos la necesidad de mejorar el proceso de admisión y las condiciones para que estos estudiantes se queden, ejecuten y hagan posible Una expansión de las políticas públicas de acción afirmativa destinadas a incluir a las poblaciones indígenas en la educación superior en el estado de Río de Janeiro.

Palabras-clave: Estudiantes universitarios indígenas; Acción afirmativa; Enseñanza superior

\section{Introdução}

No Brasil, entre os anos de 2000 e de 2010, vimos um crescimento significativo do número de estudantes indígenas nas universidades brasileiras. Esse crescimento foi fruto de diversos fatores. O principal deles foi à luta do movimento indígena, que reafirma historicamente, a necessidade concreta e atual dos povos originários em estabelecerem um diálogo mais próximo com a academia e formar seus próprios pesquisadores. Outro fator foi à ação do Ministério da Educação que, ao longo desse período, procurou cumprir as determinações do Plano Nacional de Educação e de outras diretrizes que consolidavam os direitos indígenas a uma educação intercultural, bilíngue e diferenciada ${ }^{1}$, investindo na abertura de editais que propiciaram a criação de cursos de Licenciatura Intercultural dispersos pelo Brasil, além de fortalecer o desenvolvimento de políticas de ação

\footnotetext{
${ }_{1}^{1}$ As principais leis e regulamentações que garantem o direito dos povos indígenas a uma educação escolar diferenciada, específica, bilíngue e intercultural e a obrigação do Estado de prove-la são: "Lei de Diretrizes e Bases da Educação Nacional", n. 9394, de 20/12/96, art. 78 e 79; "Referencial Curricular Nacional para as Escolas Indígenas (RCNEI), publicado em 1998; "Diretrizes Nacionais para o funcionamento das escolas indígenas-Resolução da Câmara de Educação Básica (CEB) no 3, de 14/12/1999 e a Lei 10.172, promulgada em 9/1/2001, que institui o Plano Nacional de Educação (PNE).
} 
afirmativa para o ingresso em diferentes cursos nas universidades. Outra medida importante foi o desenvolvimento de um programa de bolsas exclusivamente voltado para a permanência de estudantes indígenas e quilombolas nas universidades. Entretanto, todas essas conquistas desaparecem gradativamente a partir do ano de 2016, quando o país vive um traumático processo de impeachment e em seguida, tem um candidato da extrema direita e declaradamente anti-indígena eleito como Presidente do país ${ }^{2}$.

Nesse artigo apresentamos parte da Dissertação de Mestrado ${ }^{3}$ realizada entre os anos de 2014 e 2016, que procurou discutir a trajetória de universitários que se declaram indígenas em universidades do estado do Rio de Janeiro. Nossa preocupação, naquele momento, era discutir o contexto de acesso e de permanência desses estudantes e as condicionantes existentes para a garantia do direito ao ensino superior para universitários indígenas no estado do Rio de Janeiro. Importante salientar que a importância do trabalho se dava pela escassez de pesquisas sobre esse tema e a inexistência de censos que revelassem o número de estudantes indígenas nas universidades fluminenses. Por conta dessa dificuldade em encontrar dados sobre o tema, optamos por utilizar a técnica conhecida como snowball ou "bola de neve" (Biernacki \& Waldorf, 1981; Goodman, 1961) para localizar universitários que se reconhecessem como indígenas ${ }^{4}$ e que estivessem matriculados em cursos de graduação em universidades públicas ou privadas no estado do Rio de Janeiro.

Da primeira a última entrevista foram necessários seis meses no total, sendo as cinco primeiras realizadas no período de agosto a novembro de 2013 e a segunda parte, ou seja, as outras duas entrevistas foram realizadas no período de setembro a outubro de 2015. Esse intervalo de realização entre as entrevistas se deu pela dificuldade para localizar esses estudantes universitários indígenas e por termos vivido diferentes momentos de paralisações nas universidades públicas do Rio de Janeiro devido a cortes orçamentários e a crise financeira vivenciada no estado em diferentes momentos da história recente. Quanto aos locais das entrevistas, foram realizadas em locais de escolha dos entrevistados, totalizando cerca de uma hora de duração cada uma. Foram gravadas em meio digital com autorização dos entrevistados e transcritas para posterior análise de conteúdo (Bardin, 2011).

As entrevistas foram realizadas, a partir de um roteiro preestabelecido com perguntas em torno de quatro principais eixos: trajetória educação básica; acesso e cotidiano no ensino superior; relação com a comunidade étnica de origem e, por último, a percepção desses jovens sobre as políticas de ação afirmativa, mais precisamente, o estabelecimento de cotas para estudantes indígenas em universidades públicas. Nas transcrições das entrevistas, respeitamos o fluxo das falas e procuramos respeitar as escolhas discursivas de todos os participantes. Devido a limitação de espaço, neste artigo iremos abordar apenas três dos eixos temáticos tratados pelos estudantes indígenas.

\footnotetext{
2 Desde a campanha eleitoral, foram inúmeras as declarações do Presidente Jair Bolsonaro contra os direitos dos povos indígenas. Utilizou, inclusive, seu primeiro discurso na sessão de abertura da Assembleia Geral da ONU (setembro de 2019), para apresentar seu programa de ultradireita, pró-ditadura militar e anti-indígena para o Brasil. Na ocasião, o ultraconservador repetiu ao mundo que não haverá nova demarcação de terras indígenas no Brasil e ainda atacou a extensão das atuais reservas. Destinou ataques a lideranças indigenas e a ONGs indigenistas e ambientalistas, denominados como "peça de manobra por governos estrangeiros na sua guerra informacional para avançar seus interesses na Amazônia”. Ver: EL Pais, setembro de 2019. ${ }^{3}$ Dissertação de Mestrado autores.

${ }^{4}$ Importante salientar que o critério utilizado para a definição "ser universitário indígena" foi o de autorreconhecimento (o entrevistado se reconhece como indígena) e o de reconhecimento por parte de outros universitários indígenas que vivem no estado do Rio de Janeiro.
} 
Integraram o grupo de entrevistados seis homens e uma mulher. Todos adultos com idades entre 24 e 42 anos, sendo que seis dos sete entrevistados vivem no subúrbio da cidade do Rio de Janeiro e um deles na cidade de Belford-Roxo na Baixada Fluminense - Grande Rio. Em relação as suas etnias e tempo de moradia no estado do Rio de Janeiro, organizamos uma tabela abaixo:

Tabela 1

Grupo de universitários indígenas localizados no Rio de Janeiro

\begin{tabular}{|c|c|c|c|c|}
\hline Etnia/região & Gênero & Tempo no RJ & Curso & Universidade/ perfil \\
\hline $\begin{array}{l}\text { Guarany Mbyá } \\
\text { (Espírito Santo) }\end{array}$ & Homem & 3 anos & Ciências Sociais & pública/cotista \\
\hline $\begin{array}{l}\text { Aruak - Baré/ Saterê - } \\
\text { Mawé } \\
\text { (Manaus) }\end{array}$ & Homem & 14 anos & História & pública/cotista \\
\hline $\begin{array}{l}\text { Xavante } \\
\text { (Mato Grosso) }\end{array}$ & Homem & 4 anos & Letras & $\begin{array}{l}\text { Privada/bolsista } \\
\text { financiado por } \\
\text { instituição religiosa }\end{array}$ \\
\hline $\begin{array}{l}\text { Wapichana } \\
\text { (Roraima) }\end{array}$ & Homem & 6 anos & Administração & $\begin{array}{l}\text { Privada/programa de } \\
\text { descontos da } \\
\text { universidade }\end{array}$ \\
\hline $\begin{array}{l}\text { Tupinambá } \\
\text { (Bahia) }\end{array}$ & Homem & 20 anos & $\begin{array}{l}\text { Gestão em } \\
\text { Marketing }\end{array}$ & $\begin{array}{l}\text { Privada/ programa de } \\
\text { descontos da } \\
\text { universidade }\end{array}$ \\
\hline $\begin{array}{l}\text { Tupinambá } \\
\text { (Bahia) }\end{array}$ & Mulher & Nascida & $\begin{array}{l}\text { Comunicação } \\
\text { Social }\end{array}$ & $\begin{array}{l}\text { Privada/ programa de } \\
\text { descontos da } \\
\text { universidade }\end{array}$ \\
\hline $\begin{array}{l}\text { Pataxó } \\
\text { (Bahia) }\end{array}$ & Homem & 6 anos & Pedagogia & $\begin{array}{l}\text { Privada/ programa de } \\
\text { descontos da } \\
\text { universidade }\end{array}$ \\
\hline
\end{tabular}

Fonte: Autor, 2016.

A partir dessa mostra, vemos que diferente do que imaginávamos no início de realização dessa pesquisa, a maior parte dos universitários indígenas não estudavam em universidades públicas, mas em instituições privadas, e nenhum deles contava com bolsas do Programa Universidade para Todos - PROUNI ${ }^{5}$. Eram beneficiados com descontos internos oferecidos pelas respectivas instituições em que estudavam ou financiados por organizações religiosas ${ }^{6}$. Outra observação importante foi à dificuldade de os próprios entrevistados indicarem outros universitários indígenas em nosso estado, o que indica a ausência de espaços de acolhimento e/ou de fortalecimento étnico no espaço urbano ou nas universidades para esse conjunto populacional.

${ }_{5}^{5}$ O PROUNI é o programa do Ministério da Educação, criado pela Lei no 11.096, de 13 de janeiro de 2005, que concede bolsas de estudo integrais e parciais de $50 \%$ em instituições privadas de educação superior, em cursos de graduação e sequenciais de formação específica, a estudantes brasileiros sem diploma de nível superior.

${ }^{6} \mathrm{~A}$ instituição religiosa evangélica em questão é a AMIBEP - Associação Missionária Beneficente Proclamar que oferece não apenas o financiamento do curso, como também oportunidade de moradia e alimentação. Com o objetivo de promover o estudo da Bíblia e a educação em geral. Blog da instituição: http://elisanaxavante.blogspot.com.br/. 


\section{Vida Escolar: Trajetórias de Superação}

Discutir o acesso e a permanência de estudantes indígenas no ensino superior requer uma pergunta anterior: como foi a trajetória desses estudantes na educação básica? Qual a situação das escolas nas aldeias e com que condições eles contam para chegar aos cursos do ensino superior? Visto que as escolas indígenas de suas localidades não ofereciam todas as séries da educação básica, precisaram concluir o ensino básico em escolas das cidades de seu entorno. Com exceção de dois entrevistados que já nasceram na cidade, os demais cursaram o ensino de $1^{\mathrm{a}}$ a $4^{\mathrm{a}}$ séries do $1^{\circ} \mathrm{Grau}$ (atualmente denominado $1^{\circ}$ segmento do ensino fundamental) nas escolas de suas aldeias e o ensino de $5^{\mathrm{a}}$ a $8^{\mathrm{a}}$ séries (atualmente denominado de $2^{\circ}$ segmento do ensino fundamental) e o ensino de $2^{\circ}$ Grau (atualmente denominado de ensino médio), em escolas das cidades.

Ao serem questionados sobre suas trajetórias escolares, todos os entrevistados narraram aspectos mais significativos de suas trajetórias de escolarização básica, todas elas vinculadas à escola pública, primordialmente, às escolas existentes nas terras indígenas e às escolas urbanas que atendem indígenas para a continuidade da escolarização e encontramos relatos de grandes dificuldades:

Lá na terra nova só tinha até a quinta série, mas os meus primos moravam lá na terra nova, eu morava em Manaus, então eu só ia pra Manaus nas férias, eu estudava lá em Manaus mesmo, né, sempre no colégio público, né, mas os meus primos que moravam lá dentro da floresta eles só estudavam até a quinta série e depois eles tinham que ir pra cidade. (M. Aruak-Baré/Saterê-Mawé)

Então eu comecei a estudar na aldeia, né, e na minha aldeia não tinha o ensino médio, então quem terminasse o ensino infantil, o fundamental, ou ficava na aldeia ou ia fazer o ensino médio na cidade, e aí nós conseguimos, a FUNAI conseguiu alugar uma casa, e nós fomos estudar na cidade e aí muitas situações difícil, né, porque as vezes não tinha alimento, não pagava o aluguel, e aí nós passamos por situações muito difícil, mas aí nós conseguimos concluir, eu e muitos dos guerreiros da minha época, conseguimos concluir o ensino médio assim com muito sofrimento lá, na cidade. (A. Pataxó)

Quando chegou na época de estudar, meu pai deslocou a gente pra cidade, estudamos um ou dois anos na cidade, e aí voltamos novamente para outra região de mata, e aí estudamos mais uns dois, três anos e na adolescência voltei para cidade para estudar. (C. Wapichana)

Constata-se uma característica comum entre os entrevistados que tiveram descontinuidades no seu processo de escolarização básica, permanecendo períodos distintos sem estudar, seja durante o ensino fundamental, seja durante o ensino médio. Dentre os motivos relatados, o difícil trajeto aldeia-cidade-aldeia e os conflitos em contextos muito pouco receptivos à população indígena: Dentro da minha aldeia, só existia sala multi-seriada e quando eu cheguei ao ginásio eu tinha que ter outra opção de estudo, eu tinha que fazer o ginásio na cidade mais próxima de lá da minha aldeia, em Caramuru, na Bahia. Não se permitia presença indígena, nem na cidade, tão menos nas salas de aula. Por isso os conflitos existiam, os donos da cidade eram fazendeiros, coronéis. Então, assim, nossa presença na cidade nunca era bem-vinda apesar de a gente fornecer os alimentos para a cidade no final de semana, mas circular pela cidade não era interessante pela nossa segurança e para não criar um mal-estar. (...) Então, isso [A violência] dificultava os meus 
estudos. Acabava não indo muito para a escola, por causa de mal-estar e era muito mais a questão da violência. A violência que atrapalhou muito mais todos nós na região. (A. Tupinambá)

Como aponta Cardoso de Oliveira (1996), quanto mais próximo de um território indígena, mais acirrados são os conflitos culturais e econômicos vivenciados por essas populações. Portanto, estudar nas escolas públicas situadas em cidades próximas aos territórios e aldeias indígenas é sempre um imenso desafio para esses estudantes: diferenças linguísticas, culturais e uma rotina de preconceito e discriminação. São altas as taxas de violência contra indígenas na Bahia, Mato Grosso, Espírito Santo e Mato Grosso do Sul ${ }^{7}$, por exemplo, estados onde quatro dos universitários indígenas entrevistados completaram a educação básica.

Apesar das dificuldades, as experiências e trajetórias dos entrevistados no seu processo de escolarização básica destacam a educação escolar na cidade como emblemática neste processo. A escola da cidade, segundo os entrevistados, constituia-se como um espaço potencial das experiências de preconceito:

Eu estudei até uns 7 anos de idade dentro da aldeia, lá em Mato Grosso do Sul e fui alfabetizado em língua portuguesa, mas naquela época era muito difícil assim, ter um professor bilíngue dentro da aldeia, era mais FUNAI e eu estudei até $4 \mathrm{a}$ série, na $5^{\mathrm{a}}$ série tive que fazer numa escola rural, que não era mais dentro da aldeia. Então, fica difícil quando você lembra das coisas do passado. Até hoje, às vezes, você não quer lembrar das coisas que você viveu, que você sofreu durante a sua trajetória de vida. Por exemplo, na zona urbana, eu era o único índio, tinha que estudar no meio dos filhos dos fazendeiros. Então teve essa relação "que eu sou o melhor do que você" e isso até hoje existe. (Ab, Guarany Mbyá)

\section{Coletividade e Individualidade ${ }^{8}:$ A Difícil Trajetória nas Universidades}

No grupo entrevistado, os relatos evidenciam que as escolhas dos cursos pelos estudantes indígenas foram também pautados no compromisso com o retorno dos conhecimentos aprendidos e sistematizados à comunidade. Muitas das falas sinalizaram a preocupação com uma coletividade indígena na escolha de seu curso:

[O curso de administração] não foi algo que eu gostaria de fazer, foi algo pensando no coletivo. O maior problema dos povos indígenas, especialmente nas organizações indígenas, associações ou qualquer outra organização indígena, o maior problema é o gerenciamento. É gestão. Então, a administração vai me dar uma visão melhor e quem sabe eu posso ajudar algumas organizações preparando eles. Também, depois de ter uma formação legal, fazer cursos preparatórios, oficinas de esclarecimento de lei, como deve funcionar uma organização. Um papel importante pra gente, porque

\footnotetext{
7 Segundo relatório "Violência Contra os Povos Indígenas", publicado pela organização não-governamental Conselho Indigenista Missionário (CIMI), foram registrados, em 2014, 138 assassinatos e 135 casos de suicídios de indígenas em todo o país. No sul da Bahia e no Mato Grosso do Sul foram 41 assassinatos e 48 suicídios. Embora o Mato Grosso do Sul concentre 9\% dos índios brasileiros, as terras demarcadas no Estado correspondem a menos de 1\% das áreas indígenas no Brasil. A situação é mais dramática para os Guarani Kaiowá: foram 390 índios guarani kaiowá assassinados nos últimos 12 anos, e outros 777 se mataram desde 2000 "pela falta de perspectivas de futuro e pelos conflitos decorrentes da insuficiência de terras", registra o documento.

${ }^{8}$ Conceitos que aparecem como categorias dos próprios informantes/interlocutores da pesquisa.
} 
precisa estar com tudo documentado, senão você passa a ser um "fora da lei" (Rs) e isso tem prejudicado muito as organizações [indígenas]. (C. Wapichana)

Eu quis trabalhar com a educação, porque com a educação eu conseguiria mudar algumas coisas para o meu povo, dentro da minha aldeia, principalmente o fortalecimento da cultura e preservação. Então eu dentro da escola ou na direção da minha escola, eu via, eu vejo que eu tenho possibilidade de estar protegendo mais o meu povo... Então, com a educação nós conseguimos avançar mais, então, eu optei por pedagogia. (A. Pataxó)

De acordo com Souza (2016, pp. 157 - 158):

A decisão de sair da aldeia é parte de um compromisso tácito com o grupo, e que poderá até mesmo ser afiançado por suas lideranças. Dessa forma podemos pensar no jovem estudante indígena como um "indivíduo coletivo".

Como aponta Amaral (2010, p. 141):

O sentido coletivo ou comunitário presente no universo e no cotidiano indígena evidencia uma diferença significativa quando se definem políticas de cotas, políticas afirmativas ou qualquer outra política social voltada aos povos indígenas. Além dos interesses de ascensão ou sucesso profissional individual para o mercado, comumente observados em estudantes universitários negros ou oriundos da escola pública no contexto e na organização social capitalista, os estudantes indígenas carregam consigo as vivências, os pertencimentos culturais, as expectativas e as necessidades coletivas de sua aldeia ou comunidade.

Ainda de acordo com Amaral (2010, p. 141):

Constata-se que essa dimensão coletiva, diferente para cada grupo étnico e culturalmente explicitada por estes sujeitos na sua forma de organização social e política, se coloca, ainda que muitas vezes não intencionalmente, como uma contrarreferência aos princípios e valores pautados no individualismo, na acumulação pelo lucro e na propriedade privada, características da tradição capitalista de organização da sociedade.

Souza Lima e Hoffmann (2007, p.13) contextualizam e defendem que: As políticas de ação afirmativa, instituídas ao apagar as luzes do segundo mandato FHC, e de fato implantadas na gestão de Lula, enfrentam hoje o desafio de conhecer o mundo específico da educação escolar indígena. Precisam adequar-se mais amplamente às especificidades da situação indígena, criando mecanismos de acesso à universidade que não reproduzam pura e simplesmente as alternativas para o contexto das populações afrodescendentes, levando em consideração a necessidade de instituir políticas voltadas para povos, isto é, capazes de beneficiar, mais do que indivíduos (ainda que por meio deles), coletividades que pretendem manter-se culturalmente diferenciadas.

Ao refletir sobre a distinção dos processos de seleção de candidatos indígenas e negros para o ensino superior e afirmar a dimensão coletiva das ações afirmativas, Luciano (2006, pp. 166-167), afirma que: 
Para nós esse é o ponto nevrálgico quando tratamos de ações afirmativas. Elas estão voltadas para os indivíduos ou para os povos historicamente excluídos e oprimidos? Os indivíduos podem ter ou não ter vínculo sociopolítico com as coletividades étnicas. Salientamos que será muito mais fácil trabalhar com indivíduos indígenas dissociados de suas comunidades, pois atende exatamente à racionalidade individualizante do modelo educacional escolar tradicional-europeu vigente. Temos a convicção de que para os povos indígenas (enquanto coletividades) não interessa apenas a capacitação de indivíduos, mas as responsabilidades desses indivíduos na vida das comunidades. Daí a necessidade de articulação entre os interesses individuais, as funções sociais e as organizações sociopolíticas dos povos.

Ao apresentar os debates e sínteses sobre o ensino superior, produzidos e documentados pelos povos indígenas no Brasil e na América Latina, Souza Lima e Hoffmann (2007, p. 23) corroboram com esta perspectiva, explicitando:

A necessidade de se estabelecer como prioridade das políticas de Estado e de governo, no caso dos povos indígenas, a formação de indivíduos comprometidos com a defesa dos interesses coletivos destes povos, e não tanto com a promoção de projetos individuais de ascensão social.

A perspectiva refletida e explicitada contribui para a ressignificação do conceito de ação afirmativa, podendo indicar uma compreensão diferenciada e num novo direcionamento em torno das políticas de acesso e permanência dos estudantes indígenas na universidade, assim como afirmam Lima e Hoffmann (2007, pp. 17-18):

É preciso ter muito claro que os acadêmicos indígenas são jovens que podem ser fenotipicamente muito parecidos com os habitantes regionais com que convivem. Chegam ao ponto de, como dito antes, serem invisíveis enquanto integrantes de coletividades etnicamente diferenciadas para seus professores e para a estrutura universitária em que se inserem. Mas o fato é que diferem dos outros estudantes regionais, pobres, negros, brancos, por seus sistemas de valores e de pensamentos, por seus conhecimentos, por sua visão de mundo em última instância, por suas redes de parentesco e relacionamento e, não esqueçamos, por saberem-se portadores de identidades diferenciadas hoje em dia apoiadas em direitos coletivos. Os indígenas são, também, portadores da consciência acerca do peso do sistema de preconceitos que incide sobre eles - muito distinto do relativo aos afro-descendentes - em razão dessa trama de estereótipos, verdadeiras narrativas historicamente construídas ao seu redor. Parte dos efeitos dessa trama é reduzir a rica diversidade de seus modos de viver a um ente único e genérico, que todos nós brasileiros, negros, brancos, filhos de imigrantes, supomos conhecer - "o indio".

São escassas as pesquisas sobre a trajetória de indígenas egressos do ensino superior. Ao conhecermos essas falas reconhecemos a importância da realização de pesquisas que acompanhem a trajetória desses egressos indígenas para que seja possível medir os impactos do ensino superior para essas comunidades.

Ao serem questionados se já sofreram algum tipo de constrangimento por serem indígenas, todos citaram experiências de preconceito e de discriminação, seja na universidade, seja na cidade, como no uso de transportes públicos ou na prestação de serviços. Os não indígenas atribuem aos indígenas estereótipos e características que os classificam dentro de um estigma tribal (GOFFMAN, 
2008). Os estigmas atribuídos aos indígenas e a imagem construída historicamente ao longo dos anos, faz com que estes sejam vistos pelos estudantes não indígenas como "diferentes" dos demais. Como posto por Goffman (2008), as pessoas que não possuem os atributos socialmente considerados normais, naturais e comuns pela sociedade ou determinado grupo social, são estigmatizados. E, certamente, fica difícil a adaptação do grupo na estrutura individualista, etnocêntrica e monocultural que está bastante presente na estruturação do ambiente da educação superior:

Eu vou ser sincera, eu não gosto da estrutura acadêmica, porque eu não me encontro na estrutura acadêmica. Assim, quando eu falo dentro da [estrutura acadêmica],como posso dizer? Posso estar falando bobagem, mas é muito pessoal também. Mas, dentro da estrutura acadêmica, tudo que está lá é como um amigo da etnia Malês, da África, ele fala assim: "Tudo que está na universidade, de certa forma, fica batendo na sua identidade". Tem toda uma estrutura, um outro olhar sobre tudo, né, e que você tem que se adaptar e tem que usar como ferramenta. (R. Tupinambá)

Para Amaral (2010) ao se depararem com outro modo de vida, onde os valores são distintos, é que surge o sentimento de estrangeirismo, aqui compreendido como a sensação de não pertencer àquele lugar. Ainda para este autor, a universidade é um espaço em que as fronteiras étnicas e sociais se manifestam, é na relação com o outro que as especificidades passam a se revelar aos estudantes indígenas.

O conceito apresentado por Amaral (2010) contribui para revelar e fundamentar a presença que os acadêmicos indígenas passam a ter no ambiente universitário. Considerando a construção da categoria estudante indígena universitário e por consequência, a sua condição estrangeira para as sociedades não indígenas, fundamentalmente as que convivem no meio urbano e universitário, significa reconhecer as relações por eles estabelecidas e que lhes conferem identidade e semelhança. Sentir-se estudante indígena provoca, dessa forma, a esse acadêmico, sentir-se indígena em meio à hegemônica, homogênea, majoritária e massificada presença social e cultural não indígena na cidade e na universidade.

Ao reconhecer a atuação desses sujeitos em potencial fronteira entre universos sociais e culturais distintos (na relação entre o local e o nacional, entre a aldeia indígena e a cidade, entre os conhecimentos acadêmicos e os saberes tradicionais, entre grupos étnicos diferentes, dentre outros), se evidencia primeiro, que tais fronteiras existem e persistem apesar do fluxo de pessoas que as atravessam. Segundo Barth (1998, p.188), ao tratar do caráter das fronteiras étnicas:

As distinções de categorias étnicas não dependem de uma ausência de mobilidade, contato e informação. Mas acarretam processos sociais de exclusão e de incorporação pelos quais categorias discretas são mantidas, apesar das transformações na participação e na pertença no decorrer de histórias de vidas individuais [...] descobre-se que relações sociais estáveis persistentes e muitas vezes de uma importância vital, são mantidas através dessas fronteiras e são frequentemente baseadas precisamente nos estatutos étnicos dicotomizados [...] as diferenças culturais podem permanecer apesar do contato inter-étnico e da interdependência dos grupos.

Nessa lógica, os processos de escolarização formal, seja na escola (no nível da educação básica dentro ou fora da terra indígena), seja na universidade (no nível do ensino superior), são potenciais espaços em que as fronteiras étnicas e sociais se manifestam, provocando os sujeitos indígenas a se reconhecerem enredados e implicados ao seu universo étnico-cultural 
e a reconhecerem as diferenças dos outros, na relação direta e intercambiada com eles. (Amaral, 2010).

Em relação ao acesso de indígenas no ensino superior, essa demanda inclui a busca de reconhecimento da necessidade do diálogo entre universidade e conhecimentos tradicionais, o que implicaria espaço para outros saberes, outros cursos, outras grades curriculares. Nesse depoimento, esse estudante fala da necessidade do respeito e o reconhecimento da diversidade cultural e da valorização dos conhecimentos indígenas dentro do sistema acadêmico:

Quando se fala de melhorar é principalmente ter respeito, né, ter respeito pelos grupos indígenas, respeito pelos conhecimento, né. E assim, abordar o conhecimento assim do índio, dentro da universidade, nas matérias, assim. (A. Guarany Mbyá)

Após uma década do ingresso dos primeiros estudantes indígenas nas instituições públicas de ensino superior, a meta de efetivação de políticas de educação superior indígena desloca seu foco de atenção do tema da acessibilidade/ingresso para exigir uma atenção maior às políticas de manutenção e permanência destes estudantes nos cursos. Trata-se de repensar estratégias que contribuam, em curto prazo, para a configuração de um terreno propício à produção de novas sensibilidades, estruturas e práticas acadêmicas que valorizem e "levem a sério" os estudantes indígenas. A esse respeito, Souza Lima e Hoffmann (2004, p. 20) observam:

Levar a sério a presença de alunos indígenas dentro das universidades implicaria em criar interfaces para o diálogo, por exemplo, incorporando cursos sobre Direito indígena nos currículos das universidades e ter profissionais capazes de ministrá-los. Significaria oferecer cursos de línguas indígenas, mas ministrados por indígenas que não necessariamente precisariam ser portadores de graus universitários, ou contar com xamãs dentro de faculdades da área de saúde, reconhecendo a autoridade intelectual dos portadores de conhecimentos tradicionais.

Consoante a essa perspectiva, Marcos Paulino (2008) aponta que, "os povos indígenas na universidade podem mostrar, com toda a sua pluralidade, que existem outras formas de ser/estar no mundo que vão além da matriz eurocêntrica hegemônica".

Apesar de reconhecerem que a universidade representa inúmeras dificuldades, ao mesmo tempo reconhecem que também proporcionam conhecimentos vistos como fundamentais para se lutar por direitos, conforme verificamos nestes relatos:

Você tem que de apoderar dele [do conhecimento universitário] e usar como ferramenta, saber usar como ferramenta. Se você não sabe usar como ferramenta, às vezes, você se perde dentro daquela estrutura toda e quando você é de outro povo, então, assim, às vezes é muito difícil aceitar algo de que não se acredita. A gente entende que é necessário. Toda a sociedade envolvente a nossa volta, né, torna tudo isso necessário, a gente sabe que é necessário. Então, a gente se apodera enquanto ferramenta, né, se apodera pra poder, como posso dizer? Representar nosso grupo étnico dentro daquelas profissões, né. (R. Tupinambá)

A universidade ela te empodera, ela te instrumentaliza, pra você lidar com essas questões então foi muito bem proveitoso, foi ótimo, pra mim foi a melhor coisa que eu fiz na minha vida meu amigo. (M. Aruak-Baré/Saterê-Mawé) 
Ao refletir sobre a lógica ocidental hegemônica na universidade, Luciano (2007, p.59), também manifesta sua percepção diante do não reconhecimento e por vezes, desqualificação dos conhecimentos indígenas pela ciência não indígena:

No caso das universidades há um grave problema: os nossos conhecimentos tradicionais, os que vêm dos nossos povos, continuam sem validade nenhuma. Eles não são considerados. Servem para reflexões, para estruturar várias possibilidades, mas não têm valor. Imaginem que eu tenha que dar um parecer técnico. Eu não posso dá-lo a partir do conhecimento de meu povo. Eu seria obrigado a fazê-lo a partir da ciência ocidental, portanto, da ciência do branco, um modelo absolutamente ocidental, baseado no saber não indígena.

A demanda pela dialogicidade entre diferentes lógicas e conhecimentos se apresenta como um significativo desafio para uma estrutura que possui em sua gênese histórica de constituição o desconhecimento e a negação dos povos indígenas como sujeitos epistêmicos. Esse desafio é refletido por Silva (2007, pp. 135-136):

É necessário entender a estrutura científica do pensamento indígena. E isto não é simples: colocar os saberes em pé de igualdade científica, conseguir posicioná-los em um mesmo patamar, com igual status, é muito complicado. Estabelecer um diálogo entre os saberes é algo complexo na academia, porque temos conhecimento de que a nossa ciência ocidental fundou-se na questão da fragmentação dos conhecimentos e em um modelo homogêneo, como uma verdade que é construída. Existem, de fato, "verdades". Ora, existem outras lógicas, outros jeitos de explicar o mundo, a natureza. E isso mexe com muita gente e nos obriga a pensar.

Todos os entrevistados falam da importância da universidade, em diferentes aspectos, porém neste depoimento fica claro que a educação reconhecida por eles é um dos elementos chaves para a viabilização de seus projetos de autonomia e sustentabilidade principalmente no tocante ao maior conhecimento sobre direitos indígenas. Constata-se que, mesmo com a hegemônica forma eurocêntrico-ocidental, hierarquizada e não indígena das universidades brasileiras, os conhecimentos adquiridos e refletidos pelos estudantes indígenas provocaram neles uma leitura mais ampliada e crítica sobre o seu papel nas sociedades indígenas e não indígenas. Essa constatação se evidencia nos relatos desses estudantes indígenas que passam a articular os conhecimentos acadêmicos debatidos na universidade com as necessidades, realidades e possibilidades de autossustentabilidade de suas comunidades:

A importância que eu vejo até agora [da universidade] é conhecer o que os nossos governos estão colocando pra indígenas, não somente pra indígenas, mas pra o povo. Eu tenho aprendido as leis indígenas e isso tem me dado esperança. Porque eu conhecendo a lei, o que ela que diz a respeito do indígena, eu vou ter facilidade de falar pra eles e não brigar, porque muitos advogados, a FUNAI, antropólogos, acham que quando o índio é convidado pra isso, ele não sabe falar. É claro, "nunca estudou como é que vai falar?" Então hoje eu tenho esperança de falar da temática indígena e isso [a Lei] tá dizendo e por isso tem que ser assim. Não vai pegar borduna pra espantar todo mundo por causa disso. Quando o índio estuda, se ele tem entendimento pra o bem da comunidade, ele leva o melhor pra o branco. Apresenta, briga. É por isso que muitos estão morrendo, por não saber lidar. O fazendeiro vai lá e mata ele e ninguém fala. Hoje não vemos isso, os índios já estão andando e conhecendo as leis dele, então tem que ter prova. Isso tem me dado esperança ter aprendido. (S. Xavante) 
Neste outro depoimento dessa estudante, ela ressalta que apesar de não gostar da estrutura acadêmica, a universidade lhe oferece a oportunidade de troca de experiências, levando o diálogo intercultural para dentro da universidade:

Mesmo eu não gostando da estrutura dela [da universidade] ela te abre olhares, ela te mostra pessoas diferentes de você, e são outros olhares, são outras pessoas. Então, eu vejo a universidade como um espaço de abrir seu olhar pra o mundo, né, principalmente quando você tá na comunidade, dentro da comunidade você está em outro mundo. Não é o mesmo mundo, é outro mundo. Quando você sai da comunidade você carrega aquele mundo dentro de você. Quando você se depara com outros mundos, acho até algo interessante, que acho que Paulo Freire fala disso também, da leitura que se faz, eu não lembro direito, mas é uma leitura que você faz do mundo, né, e cada pessoa faz a sua leitura do mundo. E pra mim mudou minha leitura de muitas coisas, e ao mesmo tempo fortaleceu muito a minha questão da identidade, porque, às vezes, quando você se depara com um diferente você realmente vê, você se reconhece e vê quem você é de verdade. (R. Tupinambá)

A importância da definição de espaços e momentos de convivência intercultural entre os estudantes indígenas e os não indígenas na universidade também é encontrada em Capelo e Tommasino (2004, p. 26), quando fazem a seguinte afirmação:

A convivência de jovens índios nas universidades e nas casas de estudantes universitários certamente estimulará relações interculturais desencadeadas no calor do cotidiano escolar. Esse diálogo, ainda que tímido, pode constituir-se como o ponto desencadeador de relações interculturais baseadas no reconhecimento e valorização das diferenças culturais.

Neste aspecto, Grilo (2007, p.144) afirma que:

Deve-se garantir espaços e mecanismos de afirmação da sócio diversidade indígena na universidade, nela construindo campos interativos que possibilitem aos estudantes indígenas encontrarem-se, discutirem e divulgarem suas identidades. Tendo ali um espaço coletivo, eles poderão ser reconhecidos como um grupo social, pluriétnico, trazendo a discussão para a universidade. A fim de garantir isto, não basta haver um curso específico ou alguns estudantes que entrem em um ou outro curso.

Para além das possibilidades de interculturalidade na universidade, Bondin (2007, p.95) enfatiza a importância da convivência com os povos indígenas para se constituir uma verdadeira consciência nacional brasileira, sendo esta multiétnica, multicultural e multilinguística:

Consideramos como muito necessário para os povos indígenas o conhecimento e a ciência que se produzem na universidade, a fim de que garantam um melhor trânsito a eles pela sociedade nacional. No entanto, nós julgamos ser também fundamental para a sociedade nacional e para as nossas universidades a convivência com os povos indígenas, na medida em que todos esses processos em curso apresentam enormes desafios para as áreas científica, linguística, antropológica e para a história das ciências sociais. Ambos os lados têm muito a ganhar e, com certeza, precisamos pensar em outro programa que, digamos assim, corra paralelamente a todos esses já citados - um programa de formação de verdadeira consciência nacional quanto a existência de um Brasil multiétnico, multicultural, multilinguístico, consciência esta 
que nós não formamos em 500 anos de existência, pelo contrário, fomos ensinados que nós somos uma unidade, que falamos uma única língua e temos uma cultura nacional.

Constatamos recorrentes relatos dos entrevistados acerca das dificuldades financeiras para manterem-se na universidade e residirem no meio urbano. Nos depoimentos desses estudantes, fica claro que a universidade deveria garantir a permanência e conclusão do curso para os estudantes indígenas, criando mecanismos que permitam aos alunos condições de alimentação, transporte, moradia, disponibilidade de material de estudo e ressaltam a necessidade de se abrir diálogo com os próprios estudantes indígenas e suas comunidades para definir democraticamente políticas de permanência adequadas às suas necessidades concretas:

Por exemplo, na minha universidade não tive nem acesso e nem permanência, porque embora a faculdade me dê $40 \%$ de desconto, na mensalidade, é eu que pago, é eu que banco todo material, eu que banco a minha passagem, eu que banco a minha estadia, tudo que a universidade não tem preocupação alguma, quer receber metade do que, e aí em contra partida eles também querem aproveitar isso dentro das estatísticas, nós fazemos isso e tal, mas não é, você sabe que pra o ser humano se manter na faculdade precisa de transporte, alimentação, segurança, tem que ter material, tem que ter alimentação, tudo um conjunto de coisas. (C. Wapichana)

Permanecer na universidade é uma coisa complexa. Primeiro que tem os mecanismos de saudade, distância, trabalho, vivências, nova sociedade, a universidade tem várias sociedades internas, seus valores culturais, a gente tem pensado muito na produção de uma república à qual dias de sábado, dentro da universidade, ele tenha que vir a dar aula da cultura dele para outros indígenas e não indígenas. O que fortalece ele, culturalmente, dentro dessa sociedade, e valorar ele, ele vai se valorar e valorar a cultura do outro, aprender sobre a cultura do outro. Então, esse é um dos mecanismos. (A. Tupinambá)

Deixam claro também quanto a necessidade de criação de um local de convivência atento às especificidades dos estudantes indígenas e além disso, que esses espaços sejam administrados pelos próprios estudantes indígenas e não por interlocutores:

Com a experiência que é São Carlos, em São Paulo, a Universidade federal de São Carlos já é razoável, porque ela ajuda com moradia, ajuda com alimentação, ajuda com uma série de coisas, mas falta a parte de vivência, por exemplo, você precisa do local onde você precisa fazer seus cantos, suas danças, fazer rituais, você tem que ter um espaço pra isso, pra você se realimentar, tem que ter uma presença de gente da família, ou um apoio espiritual dos próprios indígenas, que por exemplo não tem, isso é uma falha nas universidades, não adianta estudar só a vaga, mas tem toda uma situação pra você permanecer, e permanecer que é difícil, você tem a saudade de casa, da sua comida, dos seus amigos, então tudo isso pesa, chega o momento que se você não tiver consciência, daquilo que você quer, do porque de você tá ali, você volta. (C. Wapichana)

Mais temáticas indígenas, curso específico de história indígena que não tem né, eu acho que isso é o principal né, e dá chance porque uma andorinha só não faz verão, como diria, mas se tiver um grupo de indígena aqui nós podemos formar um grupo 
de indígenas, nós podemos requerer uma sala só pros indígenas ou então construir uma oca ali pra nós. (M. Aruak-Baré/Saterê-Mawé)

Algo que realmente, assim, dê subsídio a essas demandas, algo que realmente atenda essas demandas, que não seja só, algo, assim, "Ah, aqui tem um espaço dentro da universidade que é só pra indígena. Vocês podem fazer o que vocês quiserem. Vocês podem desenvolver aqui várias coisas que vocês quiserem. E aí você, assim, a vezes entra nesses espaços mas não são indígenas que estão neles, né. Acho que aqui no Rio tem alguns exemplos de espaços assim, em que você entra, assim, no espaço, assim, dentro da universidade que é um espaço indígena mas não são os indígenas que estão neles, a frente deles. Então, existe muito isso, principalmente no estado do Rio de Janeiro, não em outros estados, você já vê algo mais, você já vê indígenas à frente desses espaços, né. Mas aqui no Rio de Janeiro, não, você não vê indígenas na frente desses espaços, né, você sempre vê um interlocutor, né, e acho que é isso que não tem mais necessidade de ter esse interlocutor. Eu acho que é válido todos estarem juntos, até no mesmo espaço, assim, que a troca de saberes, de conhecimento vai construir junto, né, mas eu não entendo, assim, essa necessidade, em alguns desses espaços, de ainda possuir esses interlocutores não indígenas, né, pra tomar à frente desses, de alguns desses espaços na universidade, né. (R.

Tupinambá)

Entende-se que a condição dos estudantes indígenas como sujeitos de direitos e de autonomia para definição dos investimentos na sua formação acadêmica e profissional seria mais efetiva na medida em que houvesse a adequada ampliação do valor da bolsa auxílio, possibilitando o suprimento de suas necessidades básicas de alimentação, moradia, de deslocamento, de aquisição de livros e materiais, de participação em eventos acadêmicos e principalmente o reconhecimento de sua ancestralidade ${ }^{9}$ e dos aportes que pode oferecer na produção de conhecimento e espaços de convivências atentos às suas especificidades.

\section{Ação Afirmativa e Cotas na Opinião dos Estudantes Indígenas}

Durante a pesquisa também procuramos identificar a opinião do grupo de estudantes indígenas sobre as ações afirmativas na área educacional, mais especificamente sobre as políticas de cotas com o recorte étnico racial. As ações afirmativas mediante as políticas de cotas para o ingresso nas universidades públicas têm provocado o polêmico e profundo debate sobre a função pública e social da universidade pública, democrática e brasileira. Contudo, apresenta-se ainda reduzido o número de produções acadêmicas e até mesmo debates nacionais em torno das ações afirmativas de ensino superior para indígenas no Brasil.

Ao procurarmos atualizar o estudo de Cajueiro (2008), identificamos 21 Instituições de Ensino Superior Públicas que já oferecem curso de licenciatura intercultural atualmente, sendo 16 federais e 5 estaduais. Importante ressaltar mais uma vez que as experiências de licenciaturas interculturais se apresentam como mais uma expressão afirmativa das conquistas e dos resultados

${ }^{9}$ Como aponta Souza (2016, p.153) : “A ausência de espaços que lhes permita expressar a religiosidade indígena mediante a prática dos rituais está entre os fatores de cuja falta mais se ressentem... Dentre as atividades coletivas praticadas nas comunidades, os rituais talvez sejam os mais acionados, cuja privação deve colaborar para a estadia solitária”. 
das lutas e da organização política destes sujeitos no cenário nacional, em parceria com as Instituições de Ensino Superior Públicas.

Observa-se também que o progressivo acesso dos povos indígenas às vagas no ensino superior público e privado nos cursos de graduação no Brasil passa a ampliar o direito à educação escolar a esses sujeitos, até então circunscrito ao nível da educação básica.

Pois bem, feitas essas breves reflexões iniciais, passemos as falas dos sujeitos da presente pesquisa a partir das entrevistas produzidas. Primeiramente questionamos se já tinham ouvido falar sobre as políticas de ação afirmativa. Dos sete entrevistados, apenas um afirmou nunca ter ouvido falar sobre o tema. Os demais estudantes entrevistados afirmaram que já haviam ouvido falar sobre as políticas de ações afirmativas, ressaltaram a sua importância, mas também apontaram críticas, conforme os depoimentos abaixo:

As ações afirmativas são importantes, não digo que elas sejam necessárias, no sentido de que elas precisam existir pra sempre não. O que está errado é a forma que o governo tem tratado a educação, tem tratado seu povo, esse é o problema, isso é resultado desse descaso... As cotas são necessárias nesse sentido, mas elas não são necessárias para mostrar a minha capacidade, isso que está em jogo, a gente pode viver muito bem sem utilizar esse tipo de situação. (C. Wapichana)

Pra gente é muito importante, mas não é a solução porque eu conheço muitos parentes $^{10}$, que passaram dificuldades, ainda passam dificuldades e não entraram por esse sistema porque quiseram mostrar que são capazes. $O$ governo ele quer mudar um espaço [da universidade] com as cotas, quando ele poderia estar dentro da minha comunidade fazendo algo... Já me preparando, com escola boa, preparada, pra eu conseguir passar como qualquer outra pessoa nesses espaços. (R. Tupinambá)

Uma política que tem colocado o indígena como inferior... Nós somos inteligentes como qualquer pessoa, tem que ter é uma educação de qualidade dentro das terras indígenas, dentro da aldeia. Tem que existir uma visão voltada [por parte] do Ministério da Educação para os povos indígenas e aí sim, aí nós vamos debater e discutir de igual pra igual, nós vamos fazer vestibular de igual pra igual. (A. Pataxó)

Além da crítica sobre a falta de investimentos da educação básica, que segundo a opinião majoritária do grupo, faria o sistema de cotas desnecessário, esses estudantes também questionaram a inexistência de fiscalização sobre se essas vagas para indígenas estavam de fato, sendo ocupadas por indígenas:

Eu não tenho nada contra as cotas, acho que é legal, mas se for o índio mesmo pra ocupar as vagas, porque eu acho importante as cotas, porém, muitas pessoas se passam por índio pra ocupar uma vaga que era do índio. (A. Guarany Mbyá)

É muito bagunçado o sistema de cota, não tem uma fiscalização, tem muitas pessoas dizendo que é indígena ocupando a vaga do índio e o índio mesmo de verdade que precisa, ele não tem espaço. Hoje nós temos que fazer um vestibular igual do homem branco, depois é que você vai ser integrado ao sistema de cotas, mas tem que ter mais rigorosidade, tem que ter mais investigação sobre quem está nesse sistema de cotas e como é esse vestibular para índio. (A. Tupinambá)

10 "Parente" é o termo amoroso pelo qual os descendentes indígenas de nosso país se tratam e se reconhecem uns aos outros. 
O que eu vejo é que essas políticas são muito deficientes ainda, porque quando você fala sobre direito indígena, direito à universidade e direito à educação, ou ainda o sistema de cotas para indígenas no mercado, na prática, isso não é muito válido. (A. Pataxó)

Esse último estudante continua sua fala questionando a existência de uma política diferenciada para, em seguida, defender a ideia de uma universidade específica para os povos indígenas:

Eu, na verdade, como liderança, o que mais falo e defendo é que se crie uma universidade específica para os povos indígenas, que tenha odontologia, que tenha medicina que tenha todas as outras áreas do homem branco, porque aí sim, vai funcionar. Como você vai trabalhar com um povo diferenciado se a universidade foi criada pra trabalhar com europeu? Com a elite do povo brasileiro? Quando chega um índio na universidade nem vai saber como trabalhar, então, criando uma universidade só para o indígena, aí sim ele vai saber como trabalhar a questão educacional para os povos indígenas. Então, nós queremos sim uma universidade só para indígena específica, é uma luta nossa, nós indígenas. (A. Pataxó)

Como aponta Dal bó (2018, p. 71):

... o caráter diferenciador das vagas e dos processos seletivos existe para que se respeite o direito dos povos indígenas de serem reconhecidos enquanto coletividades que possuem modos de vida diferenciados.

Esse estudante sinaliza a discussão recente e ainda incipiente sobre a criação de Universidades Indígenas no Brasil. Apesar de surgir como demanda de alguns grupos indígenas, atualmente o que se evidencia operacionalmente é a oferta de cursos de licenciaturas interculturais para a formação de professores indígenas e a constituição de políticas de acesso ao ensino superior por meio de vagas reservadas ou suplementares, mediante a realização de vestibulares convencionais ou específicos ${ }^{11}$, em universidades públicas.

A Lei de Cotas (lei 12.711), implantada em 2012, obriga as universidades federais a reservarem vagas para pardos, negros e indígenas de escola pública e o Exame Nacional do Ensino Médio (ENEM) é cada vez mais usado como porta de ingresso nas universidades públicas brasileiras.

11 Os vestibulares diferenciados/específicos têm base na Constituição Federal de 1988, que reconhece o direito dos povos indígenas a uma educação diferenciada, que respeite os modos de produção e transmissão de conhecimentos próprios de cada povo e orienta a efetivação de política nesse sentido. Parte, ademais, da consideração de que o atual modelo de escolas indígenas com currículos diferenciados traz a importância de um acesso específico que contemple e reconheça o modelo de educação diferenciada, de forma a garantir o princípio da equidade.

Além do que estabelece a legislação, algumas universidades, na maioria estaduais, possuem processos seletivos próprios para estudantes indígenas. É o caso das Universidades Estaduais do Paraná (UEM, UEL, UEPG, UNIOESTE, Unicentro, UNESPAR E UENP). Mesmo não sendo obrigatório, algumas federais também realizam vestibular diferenciado para indígenas, como a de Brasília (UnB), do Amazonas (UFAM), do Pará (UFPA), de Roraima (UFRR) e de São Carlos (UFSCar). 
Alguns estudantes sinalizaram o formato ainda limitado do modelo de cotas que não inclui formas de acesso diferenciadas para estudantes indígenas:

Eu tenho que ir pra uma universidade particular porque não consigo ingressar na pública, porque o meu ensino fundamental foi precário, porque os professores que iam dar aula lá na aldeia não eram professores preparados, eram indicados pelo prefeito, e esse professor não tinha capacidade nenhuma pra estar dentro da sala de aula dando aula pra gente. (A. Pataxó)

Outro problema nas cotas é que a gente divide ela com os negros, a cota racial. Então, essas poucas vagas, a gente ainda tem que competir com a população negra. É extremamente competitivo! E pra quem não fala português? E o acesso diferenciado pra quem veio das escolas das aldeias? Como eu disse anteriormente, povos indígenas no Brasil, nós somos invisíveis e quando tem que disputar, tem que disputar com os próprios discriminados também, então, é uma questão que eu sempre boto em dúvida sobre a validade [dessa política]. (A. Tupinambáa) ${ }^{12}$

É indiscutível que a luta pelas cotas empreendida pelo movimento negro foi essencial para a ampliação da presença de maior diversidade étnica na universidade, mas a pauta das ações afirmativas não pode ser a mesma para todos os ditos "excluídos": não existe uma mesma e única exclusão, as razões históricas são distintas, os sistemas de preconceitos idem. Em relação ao acesso de indígenas no ensino superior, essa demanda inclui a busca de reconhecimento da necessidade do diálogo entre universidade e conhecimentos tradicionais, o que implicaria espaço para outros saberes, outros cursos, outras grades curriculares.

\section{Para Concluir...}

A partir das entrevistas coletadas, assim como de outros estudos sobre o tema, podemos afirmar que os indígenas têm reivindicado a universidade enquanto espaço de formação qualificada de quadros não apenas para elaborar e gerir projetos em terras indígenas, mas também para acompanhar a complexa administração da questão indígena à nível governamental do país. Entretanto, ter acesso a esse direito significa a necessidade de ultrapassar obstáculos extremamente difíceis: a ausência de garantia de reais condições de estudo, por meio de sistemas e mecanismos que permitam ao aluno não só ingressar à universidade, mas que nela encontre condições de alimentação,

\footnotetext{
${ }^{12}$ Nas transcrições das entrevistas, respeitamos o fluxo das falas e procuramos respeitar as escolhas discursivas de todos os participantes. A partir de 2013, por força da Lei 12.711/2012 que dispõe sobre o ingresso nas instituições federais, garante a reserva de $50 \%$ das matrículas por curso e turno nas instituições federais a alunos oriundos integralmente do ensino médio público, levando em conta percentual mínimo correspondente ao da soma de pretos, pardos e indígenas no estado, de acordo com o Censo demográfico do IBGE. Desse modo, a lei faz um corte social e étnico-racial, nesse caso respeitando as proporções existentes em cada unidade federativa, de acordo com dados oficiais.

Como aponta Dal bó (2018, p. 74) na UERJ: “Nota-se que o ingresso de estudantes indígenas está conjugado ao de estudantes negros, colocando-os em concorrência pela mesma porcentagem de reserva de vagas". Lei Estadual 5346/2008, Art. $2^{\circ}$, I, in vervis:

"Art. $2^{\circ}$ As cotas de vagas para ingresso nas universidades estaduais serão as seguintes, respectivamente: I - 20\% (vinte por cento) para os estudantes negros e indígenas."
} 
transporte, moradia e disponibilidade de material de estudo, e, acima de tudo, reconhecimento de sua ancestralidade e dos aportes que pode oferecer na produção de conhecimento.

Refletir sobre o acesso de estudantes indígenas no ensino superior, portanto, supõe uma discussão sobre as bases eurocêntricas que fundaram a nossa universidade. Os depoimentos desses estudantes também nos levam ao questionamento acerca das condições atuais da Universidade no trato desta temática. Estará a universidade brasileira preparada para a recepção de alteridades étnicas, haja vista que cada etnia possui uma cultura, rituais, línguas diferentes? Quais as ações voltadas a produção de uma nova sensibilidade no conjunto da comunidade universitária, para o trato com a diferença? Enfrentando diversos percalços, esses heróis saem do interior da terra (coletividade de origem) e enfrentam um mundo que depende de sua ação e coragem - bem como do reconhecimento de importantes aliados que surgem no caminho - para assumir uma forma social, o que só é possível após a superação de muitos obstáculos. A universidade também precisa encarar esse desafio.

Como analisa Catafesto de Souza (2013) discutir ação afirmativa exige um debate mais aprofundado para que a universidade supere a centralidade da erudição abstrata, o etnocentrismo e o próprio racismo para se relacionar de maneira mais profícua com a polifonia de estudantes indígenas que ingressaram em diferentes carreiras acadêmicas. Para o antropólogo, "reconhecer a legitimidade contemporânea das alteridades originárias americanas" (p. 120) demonstra muito mais qualidade para as carreiras universitárias e contribui para a necessária construção de simetrias acadêmicas, que ultrapassem os muros das universidades e transbordem em outras relações de nossa sociedade.

Acreditamos que a presença de indígenas na universidade poderia refletir na melhoria da academia pelo fato de se ver enriquecida com a diversidade de olhares e sensibilidades na elaboração do conhecimento. Paladino (2012) e Francheto (2010) analisaram trabalhos de conclusão de curso de estudantes indígenas na graduação e na pós em diferentes universidades brasileiras e apontam a diversidade de enfoques, temas e as diferentes contribuições que esses olhares "outros" podem oferecer a produção científica no Brasil. Tornar visível a presença indígena na academia brasileira e as potencialidades dessa relação intercultural contribuem também para "melhorar o desequilíbrio nas relações dos povos indígenas com o Estado e a sociedade nacional, da qual depende a garantia dos direitos indígenas", como destaca o intelectual indígena Gersem José dos Santos Luciano (2012), visto que o reconhecimento e o respeito as contribuições desses povos são elementos importantes para a defesa de seus direitos específicos e históricos.

Finalmente, nossa pesquisa encontra muitos pontos comuns com outras pesquisas realizadas sobre o tema, conforme Brand e Calderoni (2012) apontam: a presença dos estudantes indígenas na universidade pública oportuniza ainda mais a manifestação das contradições, dos paradoxos e das incoerências que nela residem e a constituem, fundamentalmente, a partir das estratégias de ingresso e de permanência desses sujeitos no ambiente universitário. Isso implica talvez numa relativização do papel de cientista ou de educador na academia, para entrar num local desconhecido para a maioria: o universo indígena. E para conhecê-lo é preciso se despir dos préconceitos, dos prejuízos de valores e pôr em prática a alteridade. Por fim, constatamos a necessidade de se aprimorar o processo de ingresso e as condições de permanência desses estudantes, executando e viabilizando uma ampliação das políticas públicas de ação afirmativa voltada para a inclusão das populações indígenas no ensino superior no estado do Rio de Janeiro.

\section{Referências}

Amaral, W. R. do (2010). As trajetórias dos estudantes indigenas nas universidades estaduais do Paraná: Sujeitos e pertencimentos. (Tese de doutorado) Curitiba: PPGE/UFPR. 
Bardin, L. (2011). Análise de conteúdo. São Paulo: Edições 70.

Brasil. Ministério da Educação. Lei de diretrizes e bases da educação nacional: 9394. Brasília (1996).

Biernacki, P., \& Waldorf, D. (1981). Snowball sampling: Problems and techniques of chain referral sampling. Sociological Methods \& Research, 2(nov), 141-163.

Barth, F. (1998). Grupos étnicos e suas fronteiras. In: P. Poutignat \& J. Streiff-Fenart, Teorias da etnicidade seguido de grupos étnicos e suas fronteiras de Fredrik Barth. (Trad. E. Fernandes). São Paulo: Fundação Editora da UNESP.

Bondin, R. G .(2007). Rumo ao ensino superior - o que houve, o que bá e o que se espera que exista. In: A. C. De Souza Lima \& M. Barrosso-Hoffmann (Orgs.). Seminário desafios para uma educação superior para os povos indígenas no Brasil: Políticas públicas de ação afirmativa e direitos culturais diferenciados. Rio de Janeiro: Museu Nacional/LACED.

Brand, A. J., \& Calderoni, V. A. M (2012). Povos indígenas, conhecimentos tradicionais e diálogo de saberes nas instituições de educação superior: Desafios para uns e outros. (Trabalho apresentado na XVI ENDIPE - Encontro Nacional de Didática e Práticas de Ensino - UNICAMP - Campinas.

Cajueiro, R. (2008). Os povos indígenas em instituições de ensino superior públicas federais e estaduais do Brasil: Levantamento provisório de ações afirmativas e de licenciaturas interculturais. (S.1.): Trilhas de Conhecimento.

Capelo, M. R. C., \& Tommasino, K. (2004). Conflitos e dilemas da juventude indígena no Paraná: escolarização e trabalho como acesso à modernidade. Cadernos CERU, São Paulo, 15, 13-33. Recuperado de http://www.revistas.usp.br/ceru/article/view/75322

Catafesto De Souza, J. O. (2013). Perspectivas amerindias integradas ao universo acadêmico: O lugar dos indigenas na transformação polifônica da estrutura de ensino superior no Brasil. In. M. A. Bergamashi \& E. Nabarro \& A. Benites. Estudantes Indigenas no ensino superior: Uma abordagem a partir da experiência na UFRGS (pp. 113-127). Porto Alegre, Editora da UFRGS.

Dal bó, T. L. (2018). A presença de estudantes indígenas nas universidades: entre ações afirmativas e composições de modos de conhecer. (Tese, Doutorado em Antropologia Social) - Faculdade de Filosofia, Letras e Ciências Humanas, Universidade de São Paulo, São Paulo.

Franchetto, B. (Org.). (2010). Pesquisas indigenas na universidade. Rio de Janeiro: Funai.

Goffman, E. (2008). Estigma: Notas sobre a manipulação da identidade deteriorada (4.ed.). Rio de Janeiro: LTC.

Goodman, L. (1961). Snowball sampling. Annals of Mathematical Statistics, 32(1), 148-170.

Grilo, S.(2007). As experiências universitárias em curso e as propostas de trabalho. In: A. C. De Souza Lima \& M. Barrosso-Hoffmann (Orgs.), Seminário Desafios para uma educação superior para os povos indígenas no Brasil: políticas públicas de ação afirmativa e direitos culturais diferenciados. Rio de Janeiro: Museu Nacional/LACED.

Jornal El País, São Paulo, 24 de setembro de 2019. Em discurso na ONU, Bolsonaro escancara programa de ultradireita e anti-indígena. Disponível em: https://brasil.elpais.com/brasil/2019/09/24/politica/1569323723_562966.html Acesso em: 17 de marco de 2020.

Luciano, G. J. S. (2007). Ação afirmativa e direitos culturais diferenciados - as demandas indígenas pelo ensino superior. In: A. C. De Souza Lima \& M. Barrosso-Hoffmann (Orgs.). Seminário Desafios para uma educação superior para os povos indígenas no Brasil: políticas públicas de ação afirmativa e direitos culturais diferenciados (pp. 42-59). Rio de Janeiro: Museu Nacional/LACED.

Luciano, G. J. S., \& Hoffmann, M. B. \& Oliveira, J. C.(2012). Olhares indígenas contemporâneos II. Brasília: Centro Indígena de Estudos e Pesquisas (CINEP).

Paulino, M. M.(2008). Povos indígenas e ações afirmativas: O Caso do Paraná. (Dissertação, Mestrado) Universidade Federal do Rio de Janeiro, Rio de Janeiro. 
Paladino, M. (2012). Algumas notas para a discussão sobre a situação de acesso e permanência dos povos indígenas na educação superior. Práxis Educativa, Ponta Grossa, 7(Número Especial), 175-195. https://doi.org/10.5212/PraxEduc.v.7iEspecial.0008

Silva, R. H. D. (2007). As experiências universitárias em curso e as propostas de trabalbo. In: A. C. De Souza Lima \& M. Barrosso-Hoffmann (Orgs.). Desafios para uma educação superior para os povos indígenas no Brasil: políticas públicas de ação afirmativa e direitos culturais diferenciados (pp. 112-138). Rio de Janeiro: Museu Nacional/LACED.

Souza, A. C. G. de (2016). "Passou? Agora e luta!”: Um estudo sobre ações afirmativas e a presença de jovens estudantes na Universidade Federal da Babia. (Tese de doutorado) Faculdade de Filosofia e Ciências Humanas, UFBA, Salvador.

Souza Lima, A. C. de, \& Hoffmann, M. B. (Orgs.) (2007). Desafios para uma educação superior para os povos indígenas no Brasil. Trilhas de conhecimentos. Rio de Janeiro: Museu Nacional/LACED.

\section{Sobre o Autores}

\section{Kelly Russo}

Universidade do Estado do Rio de Janeiro

kellyrussobr@gmail.com

ORCID: http://orcid.org/0000-0003-1756-1173

Doutora em Educação Brasileira (PUC-Rio), Mestre em Ciências Sociais e Educação (FLACSOAR), Pós-Doutorado em Antropologia Social (PPGAS-Museu Nacional) e em Educação e Interculturalidade (Centro de Estudos sobre Etnicidade e Educação da Universidade de Montreal). É professora adjunta do Departamento de Formação de Professores da Faculdade de Educação da Baixada Fluminense (FEBF/UERJ). Na FEBF, integra o Programa de Pós Graduação em Educação, Cultura e Comunicação, onde orienta pesquisas de Mestrado em Educação, e coordena o Núcleo de Estudos sobre Povos Indígenas, Interculturalidade e Educação - NEPIIE. Tem experiência com projetos educacionais no contexto escolar e não escolar e desde 2011, é pesquisadora associada do LACED Laboratório de Pesquisas em Etnicidade, Cultura e Desenvolvimento (Museu Nacional, UFRJ). Possui projetos de extensão e de pesquisa sobre temas relacionados à educação intercultural critica, educação escolar e povos indígenas; ações afirmativas e a inserção de jovens indígenas na educação sup erior, direitos humanos e a educação brasileira.

\section{Edson Araújo Diniz}

Universidade do Estado do Rio de Janeiro

edsondiniz6@hotmail.com

ORCID: https://orcid.org/0000-0001-8446-0458

Graduação em Direito (2010) e Pedagogia (2014) pela Universidade do Estado do Rio de Janeiro - UERJ. Especialização em Direito Educacional (2016) pela Faculdade Internacional Signorelli FISIG. Mestrado em Educação (2016) pela FEBF/UERJ. Membro do Núcleo de Estudos sobre Povos Indígenas e Educação. 


\title{
Sobre o Editores
}

\author{
Juliane Sachser Angnes \\ Universidade Estadual do Centro-Oeste do Paraná (UNICENTRO) \\ Programa de Pós-Graduação em Educação (PPGE UNICENTRO) \\ Programa de Pós-Graduação em Administração (PPGADM UNICENTRO) \\ julianeangnes@gmail.com \\ https://orcid.org/0000-0002-4887-7042 \\ Graduação em Secretariado Executivo Bilíngue e em Letras - Português/Inglês pela \\ Universidade Estadual do Oeste do Paraná (UNIOESTE). Especialista em Linguística Aplicada \\ e Mestre em Letras - Linguagem e Sociedade também pela UNIOESTE. Doutora em Educação \\ pela Universidade Federal do Paraná (UFPR), linha de Cognição, Desenvolvimento Humano e \\ Aprendizagem. Realizou estágio pós-doutoral no Programa de Pós-Graduação em \\ Administração da Universidade Estadual de Maringá (UEM) no Grupo de Pesquisas em \\ Estudos Organizacionais. É professora da Universidade Estadual do Centro-Oeste \\ (UNICENTRO) vinculada ao Departamento de Secretariado Executivo e ao Programa de Pós- \\ Graduação em Administração (Mestrado Profissional). Tem experiência na docência e pesquisa \\ nas áreas de Educação e Administração, atuando principalmente nas seguintes áreas temáticas: \\ comunicação organizacional; redes solidárias; economia do bem-estar social; gestão escolar; \\ planejamento e organização de eventos; cerimonial e protocolo; etiqueta social e \\ comportamental; redação técnica oficial e empresarial; responsabilidade social; pesquisa \\ qualitativa em Ciências Sociais Aplicadas. É Líder do Grupo de Pesquisas em Gestão do \\ Conhecimento da Universidade Estadual do Centro-Oeste do Paraná. É líder do grupo de \\ pesquisa em Gestão do Conhecimento.
}

\section{Kaizô Iwakami Beltrão}

EBAPE FGV - - Escola Brasileira de Administração Pública e de Empresas

Kaizo.beltrao@,fgv.br http://orcid.org/0000-0002-3590-8057

Graduação em Engenharia Mecânica pelo Instituto Tecnológico de Aeronáutica (1974), mestrado em Matemática Aplicada pelo Instituto de Matemática Pura e Aplicada (1977) e doutorado em Estatística pelo Departamento de Estatística da Princeton University (1981). Atualmente é Pesquisador/Professor da EBAPE/FGV-RJ e responsável técnico pelos relatórios técnicos do ENADE junto ao INEP através da Fundação Cesgranrio. Tem experiência na área de População e Políticas Públicas, com ênfase em Previdência Social e Educação, atuando principalmente nos seguintes temas: bases de dados para políticas públicas, avaliações educacionais, diferenciais por sexo/raça, condições de saúde, demografia (modelagem estatística) e mortalidade. 


\section{Dossiê Especial \\ Educação e Povos Indígenas: Identidades em Construção e Reconstrução \\ arquivos analíticos de políticas educativas}

Volume 28 Número 73
4 de maio 2020
ISSN 1068-2341

\section{(c) (1) (2)}

Los/as lectores/as pueden copiar, mostrar, distribuir, y adaptar este articulo, siempre y cuando se de crédito y atribución al autor/es y a Archivos Analíticos de Políticas Educativas, los cambios se identifican y la misma licencia se aplica al trabajo derivada. Más detalles de la licencia de Creative Commons se encuentran en https://creativecommons.org/licenses/bysa/2.0/. Cualquier otro uso debe ser aprobado en conjunto por el autor/es, o AAPE/EPAA. La sección en español para Sud América de AAPE/EPAA es publicada por el Mary Lou Fulton Teachers College, Arizona State University y la Universidad de San Andrés de Argentina. Los artículos que aparecen en AAPE son indexados en CIRC (Clasificación Integrada de Revistas Científicas, España) DIALNET (España), Directory of Open Access Journals, EBSCO Education Research Complete, ERIC, Education Full Text (H.W. Wilson), PubMed, QUALIS A1 (Brazil), Redalyc, SCImago Journal Rank, SCOPUS, SOCOLAR (China).

Por errores y sugerencias contacte a Fischman@asu.edu

Síganos en EPAA's Facebook comunidad at https://www.facebook.com/EPAAAAPE y en Twitter feed@epaa_aape. 


\section{arquivos analíticos de políticas educativas conselho editorial}

Editor Consultor: Gustavo E. Fischman (Arizona State University)

Editoras Associadas: Andréa Barbosa Gouveia (Universidade Federal do Paraná), Kaizo Iwakami Beltrao, (Brazilian School of Public and Private Management - EBAPE/FGVl), Sheizi Calheira de Freitas (Federal University of Bahia), Maria Margarida Machado, (Federal University of Goiás / Universidade Federal de Goiás), Gilberto José Miranda, (Universidade Federal de Uberlândia, Brazil), Marcia Pletsch (Universidade Federal Rural do Rio de Janeiro), Maria Lúcia Rodrigues Muller (Universidade Federal de Mato Grosso e Science), Sandra Regina Sales (Universidade Federal Rural do Rio de Janeiro)

\begin{tabular}{|c|c|}
\hline Almerindo Afonso & Alexandre Fernandez Vaz \\
\hline Universidade do Minho & Universidade Federal de Santa \\
\hline Portugal & Catarina, Brasil \\
\hline Rosanna Maria Barros Sá & Regina Célia Linhares Hostins \\
\hline Universidade do Algarve & Universidade do Vale do Itajaí, \\
\hline Portugal & Brasil \\
\hline Maria Helena Bonilla & Alfredo Macedo Gomes \\
\hline Universidade Federal da Bahia & Universidade Federal de Pernambuco \\
\hline Brasil & Brasil \\
\hline Rosa Maria Bueno Fischer & Jefferson Mainardes \\
\hline Universidade Federal do Rio Grande & Universidade Estadual de Ponta \\
\hline do Sul, Brasil & Grossa, Brasil \\
\hline Alice Casimiro Lopes & Jader Janer Moreira Lopes \\
\hline Universidade do Estado do Rio de & Universidade Federal Fluminense e \\
\hline Janeiro, Brasil & $\begin{array}{l}\text { Universidade Federal de Juiz de Fora, } \\
\text { Brasil }\end{array}$ \\
\hline Suzana Feldens Schwertner & Debora Nunes \\
\hline Centro Universitário Univates & Universidade Federal do Rio Grande \\
\hline Brasil & do Norte, Brasil \\
\hline Geovana Mendonça Lunardi & Alda Junqueira Marin \\
\hline Mendes Universidade do Estado de & Pontifícia Universidade Católica de \\
\hline Santa Catarina & São Paulo, Brasil \\
\hline Flávia Miller Naethe Motta & Dalila Andrade Oliveira \\
\hline Universidade Federal Rural do Rio de & Universidade Federal de Minas \\
\hline Janeiro, Brasil & Gerais, Brasil \\
\hline
\end{tabular}

José Augusto Pacheco

Universidade do Minho, Portugal

Jane Paiva

Universidade do Estado do Rio de Janeiro, Brasil

Paulo Alberto Santos Vieira

Universidade do Estado de Mato

Grosso, Brasil

Fabiany de Cássia Tavares Silva

Universidade Federal do Mato

Grosso do Sul, Brasil

\section{António Teodoro}

Universidade Lusófona

Portugal

Lílian do Valle

Universidade do Estado do Rio de Janeiro, Brasil

\author{
Alfredo Veiga-Neto \\ Universidade Federal do Rio Grande \\ do Sul, Brasil
}




\section{archivos analíticos de políticas educativas consejo editorial}

Editor Consultor: Gustavo E. Fischman (Arizona State University)

Editores Asociados: Felicitas Acosta (Universidad Nacional de General Sarmiento), Armando Alcántara Santuario (Universidad Nacional Autónoma de México), Ignacio Barrenechea, Jason Beech (Universidad de San Andrés), Angelica Buendia, (Metropolitan Autonomous University), Alejandra Falabella (Universidad Alberto Hurtado, Chile), Carmuca Gómez-Bueno (Universidad de Granada), Veronica Gottau (Universidad Torcuato Di Tella), Carolina Guzmán-Valenzuela (Universidade de Chile), Antonia Lozano-Díaz (University of Almería), Antonio

Luzon, (Universidad de Granada), María Teresa Martín Palomo (University of Almería), María Fernández MellizoSoto (Universidad Complutense de Madrid), Tiburcio Moreno (Autonomous Metropolitan University-Cuajimalpa Unit), José Luis Ramírez, (Universidad de Sonora), Axel Rivas (Universidad de San Andrés), César Lorenzo

Rodríguez Uribe (Universidad Marista de Guadalajara), Maria Veronica Santelices (Pontificia Universidad Católica

Claudio Almonacid

Universidad Metropolitana de

Ciencias de la Educación, Chile

Miguel Ángel Arias Ortega

Universidad Autónoma de la

Ciudad de México

Xavier Besalú Costa

Universitat de Girona, España

Xavier Bonal Sarro Universidad Autónoma de Barcelona, España

Antonio Bolívar Boitia

Universidad de Granada, España

José Joaquín Brunner Universidad Diego Portales, Chile

\section{Damián Canales Sánchez}

Instituto Nacional para la

Evaluación de la Educación, México

Gabriela de la Cruz Flores

Universidad Nacional Autónoma de México

Marco Antonio Delgado Fuentes

Universidad Iberoamericana,

México

Inés Dussel, DIE-CINVESTAV, México

Pedro Flores Crespo Universidad

Iberoamericana, México

$$
\text { de Chile) }
$$

Ana María García de Fanelli

Centro de Estudios de Estado y

Sociedad (CEDES) CONICET,

Argentina

Juan Carlos González Faraco

Universidad de Huelva, España

María Clemente Linuesa

Universidad de Salamanca, España

Jaume Martínez Bonafé

Universitat de València, España

Alejandro Márquez Jiménez

Instituto de Investigaciones sobre la

Universidad y la Educación,

UNAM, México

María Guadalupe Olivier Tellez,

Universidad Pedagógica Nacional,

México

Miguel Pereyra Universidad de

Granada, España

Mónica Pini Universidad Nacional

de San Martín, Argentina

Omar Orlando Pulido Chaves

Instituto para la Investigación

Educativa y el Desarrollo

Pedagógico (IDEP)

José Ignacio Rivas Flores

Universidad de Málaga, España
Miriam Rodríguez Vargas

Universidad Autónoma de

Tamaulipas, México

José Gregorio Rodríguez

Universidad Nacional de Colombia, Colombia

Mario Rueda Beltrán Instituto de Investigaciones sobre la Universidad y la Educación, UNAM, México

José Luis San Fabián Maroto

Universidad de Oviedo,

España

Jurjo Torres Santomé, Universidad de la Coruña, España

Yengny Marisol Silva Laya

Universidad Iberoamericana,

México

Ernesto Treviño Ronzón

Universidad Veracruzana, México

Ernesto Treviño Villarreal

Universidad Diego Portales

Santiago, Chile

Antoni Verger Planells

Universidad Autónoma de

Barcelona, España

Catalina Wainerman

Universidad de San Andrés,

Argentina

Juan Carlos Yáñez Velazco

Universidad de Colima, México 


\section{education policy analysis archives editorial board}

Lead Editor: Audrey Amrein-Beardsley (Arizona State University)

Editor Consultor: Gustavo E. Fischman (Arizona State University)

Associate Editors: Melanie Bertrand, David Carlson, Lauren Harris, Eugene Judson, Mirka Koro-Ljungberg, Daniel Liou, Scott Marley, Molly Ott, Iveta Silova (Arizona State University)

\section{Cristina Alfaro}

San Diego State University

Gary Anderson

New York University

Michael W. Apple

University of Wisconsin, Madison

Jeff Bale

University of Toronto, Canada

Aaron Bevenot SUNY Albany

David C. Berliner

Arizona State University

Henry Braun Boston College

\section{Casey Cobb}

University of Connecticut

Arnold Danzig

San Jose State University

Linda Darling-Hammond

Stanford University

Elizabeth H. DeBray

University of Georgia

David E. DeMatthews

University of Texas at Austin

Chad d'Entremont Rennie Center

for Education Research \& Policy

John Diamond

University of Wisconsin, Madison

Matthew Di Carlo

Albert Shanker Institute

Sherman Dorn

Arizona State University

Michael J. Dumas

University of California, Berkeley

Kathy Escamilla

University ofColorado, Boulder

Yariv Feniger Ben-Gurion

University of the Negev

Melissa Lynn Freeman

Adams State College

Rachael Gabriel

University of Connecticut
Amy Garrett Dikkers University

of North Carolina, Wilmington

Gene V Glass

Arizona State University

Ronald Glass University of

California, Santa Cruz

Jacob P. K. Gross

University of Louisville

Eric M. Haas WestEd

Julian Vasquez Heilig California

State University, Sacramento

Kimberly Kappler Hewitt

University of North Carolina

Greensboro

Aimee Howley Ohio University

Steve Klees University of Maryland

Jaekyung Lee SUNY Buffalo

Jessica Nina Lester

Indiana University

Amanda E. Lewis University of

Illinois, Chicago

Chad R. Lochmiller Indiana

University

Christopher Lubienski Indiana

University

Sarah Lubienski Indiana University

William J. Mathis

University of Colorado, Boulder

Michele S. Moses

University of Colorado, Boulder

Julianne Moss

Deakin University, Australia

Sharon Nichols

University of Texas, San Antonio

Eric Parsons

University of Missouri-Columbia

Amanda U. Potterton

University of Kentucky

Susan L. Robertson

Bristol University
Gloria M. Rodriguez

University of California, Davis

R. Anthony Rolle

University of Houston

A. G. Rud

Washington State University

Patricia Sánchez University of

University of Texas, San Antonio

Janelle Scott University of

California, Berkeley

Jack Schneider University of

Massachusetts Lowell

Noah Sobe Loyola University

Nelly P. Stromquist

University of Maryland

Benjamin Superfine

University of Illinois, Chicago

Adai Tefera

Virginia Commonwealth University

A. Chris Torres

Michigan State University

Tina Trujillo

University of California, Berkeley

Federico R. Waitoller

University of Illinois, Chicago

Larisa Warhol

University of Connecticut

John Weathers University of

Colorado, Colorado Springs

Kevin Welner

University of Colorado, Boulder

Terrence G. Wiley

Center for Applied Linguistics

John Willinsky

Stanford University

Jennifer R. Wolgemuth

University of South Florida

Kyo Yamashiro

Claremont Graduate University

Miri Yemini

Tel Aviv University, Israel 